\title{
Integration of the dispersed generators in the distribution management system
}

DOI:

10.1109/PTC.2003.1304391

Link to publication record in Manchester Research Explorer

\section{Citation for published version (APA):}

Ciric, R. M., Padilha, A., Denis, I. F. E. D., \& Ochoa, L. F. (2003). Integration of the dispersed generators in the distribution management system. In 2003 IEEE Bologna PowerTech - Conference Proceedings/IEEE Bologna PowerTech - Conf. Proc. (Vol. 3, pp. 217-224) https://doi.org/10.1109/PTC.2003.1304391

\section{Published in:}

2003 IEEE Bologna PowerTech - Conference Proceedings|IEEE Bologna PowerTech - Conf. Proc.

\section{Citing this paper}

Please note that where the full-text provided on Manchester Research Explorer is the Author Accepted Manuscript or Proof version this may differ from the final Published version. If citing, it is advised that you check and use the publisher's definitive version.

\section{General rights}

Copyright and moral rights for the publications made accessible in the Research Explorer are retained by the authors and/or other copyright owners and it is a condition of accessing publications that users recognise and abide by the legal requirements associated with these rights.

\section{Takedown policy}

If you believe that this document breaches copyright please refer to the University of Manchester's Takedown Procedures [http://man.ac.uk/04Y6Bo] or contact uml.scholarlycommunications@manchester.ac.uk providing relevant details, so we can investigate your claim.

\section{OPEN ACCESS}




\title{
Integration of the Dispersed Generators in the Distribution Management System
}

\author{
Rade M. Ciric, Antonio Padilha, Member, IEEE, Iara Fernanda Ehrenberg Dossi Denis, \\ Luis F. Ochoa, Student Member, IEEE
}

\begin{abstract}
Since the 80s huge efforts have been made to utilize renewable energy sources to generate electric power. An important issue about using renewable energy sources is a Distribution Management System (DMS) in presence of dispersed generators. This paper reports some aspects of integration of the dispersed generators in the DMS. Besides, an investigation of impact of the dispersed generators on the overall performances of the distribution systems in steady state is performed. In order to observe losses in the distribution networks with dispersed generators, several loss allocation methods are applied. Results obtained from case study using IEEE test network, are presented and discussed.
\end{abstract}

Index Terms-- Distribution networks, dispersed generators, distribution management system, loss allocation.

\section{INTRODUCTION}

$\mathrm{V}$ arious investigations showed that dispersed generators (DGs) integrated into utilities' distribution networks (DNs) could affect the host DNs in number of ways [1]-[9]. Previous experience has shown that the integration of DGs into DNs could create safety and technical problems. They may contribute to fault currents, cause voltage flickers, interfere with the process of voltage control, increase losses, etc. Since the DNs with DGs are not passive, all issues about planning, building, maintaining and operation of the DNs become very interesting and need a reinvestigation. Actually, overall model of the distribution system should be renewed, since the impact of DGs on the DNs expansion planning and operation is significant.

The Distribution Management System (DMS) functions like load (state) estimation, power flow calculation, network reconfiguration, supply restoration, fault analysis, relay setting, $\mathrm{Q}-\mathrm{V}$ regulation etc. are significantly affected by the DGs in the DN. It means that the DMS functions should be re-considered and probably modified in order to respect the presence of DGs in the DNs. For example, the presence of DGs in the DN improves the quality of state estimation in the DN, since the voltages in the DG's nodes are observed through the RMUs. Power flow calculation is of course affected by the DGs, as well as, the network reconfiguration in order to minimize the power losses. Supply restoration after the fault of feeder or supply transformer, should respect the presence of the DGs in the DN as well, since alternate variants of power supply could be quite different

R.M.Ciric is a postdoctoral researcher at UNESP Ilha Solteira, SP, Brazil; A. Padilha is with UNESP Ilha Solteira, SP, Brazil;

I.F.E.D.Denis is a Ph.D. student at UNESP Ilha Solteira, SP, Brazil;

L.F.Ochoa is a M.Sc. student at UNESP Ilha Solteira, SP, Brazil. comparing to the passive DNs. Similarly the DGs change the voltages and reactive power flow in the DNs and consequently $\mathrm{Q}-\mathrm{V}$ regulation should be re-considered, etc. General question regarding operation of the DNs with DGs is: "What is the impact of the DGs on the overall system performance of the distribution system?"

This paper reports some aspects of integration of the DGs in the DMS. The following DMS functions in the DNs with DGs are considered: load (state) estimation, power flow calculation, voltage regulation, fault analysis and network reconfiguration. The impact of the DGs on the overall performances of the distribution systems in steady state is also investigated. In order to measure the impact of the DG on the overall distribution system performance, the following indices are proposed: total power losses, real and reactive power generation, voltage drop, sum of the squared voltage deviation, current balance of the feeders, and current balance of the supply transformers. In order to observe losses in the distribution systems with DGs, proportional sharing (PS), squared demand (SD) and direct loss coefficients (DLC) loss allocation methods are applied.

Results obtained from several case studies using IEEE 34 nodes test network are presented and discussed.

\section{POWER FLOW}

Efficient and robust power flow for large-scale real life DNs with DGs is the basic tool in DMS. Besides, power flow analysis is essential for investigating the impact of the DGs on the distribution systems in steady state. Depending on the contract and control status of the DG, it may be operated in one of the following modes, Fig. 1: 1) In parallel operation with the feeder where DG is designated to supply a large load with fixed real and reactive power output; 2) To output power at a specified power factor; 3) To output power at a specified terminal voltage.

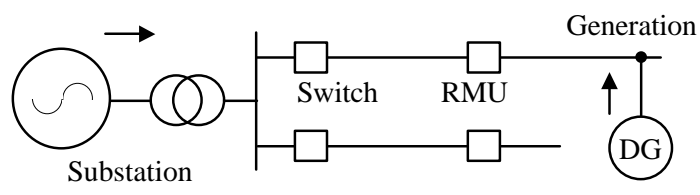

Fig. 1. Distribution network with dispersed generator.

Considering power flow, the DG node in the first two cases can be represented as a PQ node. It requires just a little modification in the power flow algorithm, actually the current is injected into the bus. In the third case where the source controls the voltage magnitude at the corresponding node, the node is 
referred to as a PV node. If the computed reactive power generation is out of the reactive generation limits, the reactive power generation is set to that limit and the unit acts as a PQ node. Some dispersed storage units may also act as a constant current but for purposes of the power flow the PQ model is adequate. In last decade, different procedures for handling PV nodes have been proposed [10]-[14]. Special single-phase and three-phase power flow methods have been developed for radial and weakly meshed network analysis. Experience showed that very good results in handling PV nodes in large-scale DNs are obtained using the backward/forward procedure, i.e. branchoriented methods. These methods may be classified as follows: current summation methods, power summation methods and admittance summation methods [14]. In the proposed methodology for determining the impact of DGs on the distribution system performance, the efficient and robust compensation method proposed in [11] is applied. In this method, PV node sensitivity matrix is used to eliminate voltage magnitude mismatch for all PV nodes. The problem of compensating PV node voltage magnitude is transferred to the determining reactive current injection for each PV node, so that the voltage magnitude of this node is equal to the scheduled value. Since relation between reactive current and voltage magnitude of the DG is nonlinear, desired reactive current of the DG is determined iteratively.

\section{State Estimation}

The results of state estimation and power flow analysis are used as input for the other DMS applications: network reconfiguration, supply restoration, voltage regulation, $\mathrm{VAr} / \mathrm{Volt}$ coordination, fault analysis, etc. Obtaining the good quality input data for the DMS applications have the priority, since the lack of input data, or the data uncertainty can generate wrong network actions. The lack of reliable input data obtained from real-time measurement makes the state estimation in the DNs very difficult task. Besides, specific nature of DNs does not allow use of approaches developed for transmission system state estimation with the redundancy of the measurement more than 2. In the reallife distribution networks just 10 to $15 \%$ of the necessary data are available from the real-time measurement (D-SCADA). Consequently, the distribution state estimation methods are based on the historical data, as well as pseudo-measurement [15]-[23]. These methods use conventional techniques based on WLS approach, sensitivity analysis, power flow analysis, realtime modeling technique or fuzzy distribution loads approach. However, independently of the used methodology, presence of DGs in the DN will improve the quality of distribution state estimation, since the voltages in the DG nodes type PV or PQ are measured by Voltage and Current Remote Measurement Units (RMU-V, RMU-C).

One state estimation algorithm in the DNs with DGs based on the historical data and real time measurement, that uses fuzzy set approach, is presented in the following.
State Estimation algorithm in the DN with DGs.

1. Reading network data;

2. Time setting: $t=00: 15 \mathrm{~h}$;

3. Reading data for instant $t$ using real-rime measurement (D-

SCADA, RMU-V, and RMU-C);

4. Load estimation using fuzzy set approach [23].

Calculation of the total feeder current, $I_{\text {total } f_{-} i}$

$$
I_{\text {total_ } f_{-} i}=I_{f i}+\sum_{j=1}^{N G i} I_{\text {genj }}, i=1, N F
$$

where:

$N F$ is the number of feeders;

$N G i$ is the number of DGs connected to the feeder $i$; $I_{f i}$ is the measured current of the feeder $i$ (D-SCADA); $I_{\text {genj }}$ is the measured current of the DG $j$ (RMU-C).

Calculation of the total section current $I_{\text {total_s_k }}$

$$
I_{\text {total } \_s \_k}=I_{s k}+\sum_{j=1}^{N G k} I_{g e n j}, k \in\{-C \text { nodes }\}
$$

where:

$N G k$ is the number of the DGs connected downstream to the section $k$;

$I_{s k}$ is the measured current in the section $k$ (RMU-C);

5. Power flow calculation in the radial network with DGs [10] using estimated load of the transformer stations medium voltage/low voltage (TS MV/LV), respecting the following boundary conditions in DG and RMU-V nodes:

$P_{j}=P_{g}, V_{j}=V_{g}, j \in\{$ set of DG-PV nodes $\}$,

$P_{j}=-P_{g}, Q_{j}=-Q_{g}, j \in\{$ set of DG-PQ nodes $\}$, and

$P_{j}=0, V_{j}=V_{m}, j \in\{$ set of RMU-V nodes $\}$,

where $P_{g}, Q_{g}$ and $V_{g}$ are real power, reactive power and voltage of the DG respectively, and

$V_{m}$ is the voltage obtained by real time measurement (RMU-V);

6. Writing state estimated values of nodal voltages and real and reactive loads: $V_{i}, \theta_{i}, P_{\text {est }-i}, Q_{\text {est- }-i}, i=1, N$, where $N$ is the number of TS MV/LV;

7. $t=t+15 \mathrm{~min}$;

8. Repeating steps 3-7 until $t=24: 00 \mathrm{~h}$.

\section{Voltage Regulation IN THE DG NODE}

Connection of the DGs in the DNs can result in voltages that may be out the statutory limit [24], [25], [26]. Generally there are two cases of DG that can operate in the DNs: induction generator (wind-turbine) or synchronous generator (gas, diesel turbine etc.). In case of wind-turbine, DG's voltage can be greater than substation high voltage/medium voltage (HV/MV). In case of synchronous generator, the substation voltage is usually maintained greater than DG node voltag. Voltage rise mismatch between generator voltage and substation voltage, $\Delta \mathrm{e} V_{r}$ in case of induction DG is given by equation (3) [24]. The voltage drop - mismatch between substation voltage and DG voltage in case of synchronous DG, $\Delta V_{d}$ is given by equation (4). 


$$
\begin{aligned}
& \Delta V_{r}=\left\{\left(P_{g}-P_{c}\right) R-\left(P_{g}+Q_{c}\right) X\right\} / V_{g}^{*} \\
& \Delta V_{d}=\left\{\begin{array}{l}
\left(P_{c}-P_{g}\right) R+\left(Q_{c}-Q_{g}\right) X+ \\
j X\left(P_{c}-P_{g}\right)+j R\left(Q_{g}-Q_{c}\right)
\end{array}\right\} / V_{g}^{*}
\end{aligned}
$$

where:

$P_{g}$ is the real power of the DG;

$Q_{g}$ is the reactive power of the DG (injection or import);

$P_{c}$ and $Q_{c}$ are the real and reactive consumer loads at the DG node;

$Z=R+j X$ is the line impedance between substation HV/MV and the DG node;

$V_{g}$ is the voltage at the DG node,

$V_{s}$ is the voltage at the substation $\mathrm{HV} / \mathrm{MV}$,

$\Delta V_{r}=V_{g}-V_{s}$ is the voltage rise in case of induction DG,

$\Delta V_{d}=V_{s^{-}} V_{g}$ is the voltage drop in case of synchronous DG.

There are several methods for reducing voltage rise in case of wind turbine DG (3): reduction of generator power input $P_{g}$, increase of generator reactive power import $Q_{g}$ or voltage regulation via load control in the DG node [24]. The generation output is reduced only at critical times to maintain satisfactory voltages. Increasing the generator reactive power import to neutralize voltage rise from the real power injection is done by static VAr compensators, switched capacitor banks or via existing inverters. Power factor control allows full generation output. Load control in reducing voltage rise is a new method [24]. Actually, when feeder voltages are at their limit, additional load is switched on to reduce voltage. Usual method for reducing voltage drop in the DNs in case of synchronous DG is increasing generator real and reactive power input $P_{g}, Q_{g}$ (4).

\section{LOSS ALlOCATION}

One of the interesting issues about DGs in the de-regulated power energy market, is the problem of loss allocation to loads and generators in the DN. Although the loss allocation issue is addressed more often to the transmission systems [27], after introducing DGs and open access electricity networks in last decade, distribution system loss allocation is turning into more interesting problem [28]. Moreover, in the de-regulated power industry, loss allocation in the DNs becomes very significant issue since the losses in the medium voltage DNs are in range of $2-5 \%$, while the losses in the low voltage network sometimes exceed $10-15 \%$. The main difficulty in allocating losses to loads is that, regardless of the approach, the final allocation always contains a degree of arbitrariness. This is the consequence of the fact that system distribution, as well as, transmission losses are a non-linear function of the node injections. As it is concluded in [27], it seems that issue of fairness will probably never be fully resolved by any loss allocation method.

In order to observe losses in the DNs with DGs, in this research three loss allocation methods are applied: proportional sharing (PS), squared demand (SD) and direct loss coefficients (DLC) method. As the name suggest, in the proportional sharing and squared demand method losses are allocated to the nodes proportionally to the load injections or to the squared demand, respectively.

Allocated losses $L(i)$ according to the DLC method are represented as follows [28]:

$$
L(i)=\gamma(i) \times P(i),
$$

where:

$P(i)$ is the real power injection at node $i$, and

$\gamma(i)$ is the direct loss coefficient of node $i$.

Direct loss coefficients are given by

$\gamma \cong \frac{1}{2}[\Delta \theta \quad \Delta V][H][\bar{J}]^{-1}$,

where:

$[H]$ is the hessian matrix,

$[\bar{J}]$ is the average jacobian computed from the flat start and final jacobians, and

$\Delta V$ and $\Delta \theta$ represent the changes in operating point.

An important characteristic of the DLC method is the possibility of negative loss allocations. Negative allocation provided monetary incentives to those DGs "well "positioned in the network. On the other side, DGs and loads "poorly" placed, receive higher loss allocations. If the node has neither load nor generation the loss allocation is zero. Since in the DN power flow calculations, losses are deemed to be supplied from the transmission network that is taken as a slack node, the lossrelated charges for this node is zero. In other words, total power losses in the DN are insensitive to changes in active and reactive injections at the slack node.

\section{FAULT ANALYSIS}

There are several efficient methods for short circuit analysis in the DNs with DGs that use symmetrical components or phase network representation. Methods that exploit actual $a b c$ phase representation allow fault analysis in the un-balanced and/or unsymmetrical DNs [29]-[33]. In this work efficient hybrid compensation method for fault analysis from [33] is applied. The method uses solution of three-phase power flow [11] as pre-fault condition and performs one backward-forward sweep to generate post-fault state after the updating hybrid current injections. Method [33] allows simulation of various types of single and simultaneous faults in large-scale real life radial and weakly meshed DNs with DGs. In this method, the internal voltage of DGs is assumed constant at the instant of the fault. The constant voltage of the DG is modeled on the following way: PV node sensitivity matrix is created and used to calculate the injection current needed to keep DG's internal voltage constant. The relation between DG's voltage and current is expressed as:

$$
\left[Z_{g}\right]\left[I_{g}\right]=\left[\Delta V_{g}\right]
$$

where:

$\Delta V_{g}$ is the vector of three-phase DG's voltage mismatch;

$I_{g}$ is a vector of the DG's injection current;

$Z_{g}$ is the complex impedance matrix with dimension $3 N_{g} \times 3 N_{g}$, ( $N_{g}$ is the number of DGs). 
Matrix $Z_{g}$ is formed by identifying the path between PV node and the root node. The internal impedance of a DG and the system equivalent impedance at the substation HV/MV are also included in $Z_{g}$.

In order to investigate effects of neutral wire and ground in case of faults, in this paper a generalized power flow algorithm which uses $5 \times 5$ network representation (abc phases, neutral wire and ground conductor) is applied in the hybrid compensation short circuit method [33].

\section{SYSTEM PERFORMANCE}

In last decade, considerable research has been conducted in the area of distribution network reconfiguration. Network (feeder) reconfiguration entails altering the topological structure of DNs by changing the open/close status of the switches under both normal and abnormal operating conditions. There are plenty of valuable papers dealing with DN reconfiguration problem in last two decades. Generally, two main DMS functions regarding network reconfiguration exist: 1) Reconfiguration for Operation Cost Reduction [34], [35], [36], and 2) Supply Restoration after the fault of feeder or supply transformer HV/MV [37]-[40]. Three main approaches for solving above-mentioned problems exist: optimization approach, heuristic approach and expert system based approach. Independently of the used approach there is a need for establishing distribution system performance indices for evaluation of each DN configuration. In this paper we propose set of performance indices for observing distribution system with DGs in steady state.

The proposed approach for observing performances of the distribution system with DGs is based on real-time power flow analysis and calculation of the various system indices. The following indices are introduced: total power losses, real and reactive power input (demand) of the DGs, maximum voltage drop, sum of the squared voltage deviation, current balance of the feeders, and current balance of the supply transformers HV/MV. The above-mentioned indices of the distribution system with EGs are defined as follows:

(1) Total Power Losses are defined by expression [28]:

$$
I L P^{h}=\frac{1}{2} \sum_{k=1}^{n} \sum_{m=1}^{n} g_{k m}\left[V_{k}^{2}+V_{m}^{2}-2 V_{k} V_{m} \cos \left(\theta_{k}-\theta_{m}\right)\right]
$$

where $h$ is the DN configuration considering status of the switches (closed-open), as well as status of the DGs (operate/ does not operate).

Low value of index $I L P^{h}$ indicates low active power losses meaning better system performance.

(2) Real DG Power Injection is defined by expression:

$$
I P G^{h}=\frac{\sum_{k=1}^{N G} P_{\text {genmaxk }}}{\sum_{k=1}^{N G} P_{\text {genk }}^{h}}
$$

where:

$N G$ is the number of DGs in the DN;
$P_{\text {gen } \max }$ is the maximum real power injection of the DG $i$;

$P_{\text {genk }}^{h}$ is the actual real power injection of the DG $i$.

Low values of the index $I P G^{h}$ indicate great active power generation in the DN meaning better efficiency of DGs.

(3) Reactive DG Power Demand is defined by expression:

$$
I Q G^{h}=\frac{\sum_{k=1}^{N G} Q_{\text {genk }}^{h}}{\sum_{k=1}^{N G} Q_{\text {gen } \max k}}
$$

where:

$Q_{\text {gen } \max k}$ is the maximum reactive power demand of the DG $i$;

$Q_{g e n k}^{h}$ is the actual reactive power demand of the DG $i$ in $h$-th

$D N$ configuration.

Low values of the index $I Q G^{h}$ indicate small reactive power demand in the system meaning smaller losses in the capacitor banks, VAr compensators or inverters.

(4) Critical Voltage Drop is defined by expression:

$$
I V^{h}=\max \left(\frac{V_{r}^{h}-V_{i k}^{h}}{V_{r}^{h}}\right)_{\substack{i=1, N F \\ k=1, N F T i}}
$$

where:

$V_{r}^{h}$ is the voltage magnitude at the substation HV/MV in $h$-th DN configuration;

$V_{i k}^{h}$ is the voltage magnitude of $k$-th distribution transformer at $i$-th feeder in $h$-th DN configuration;

$N F T i$ is the number of distribution transformers supplied by $i$ th feeder;

$N F$ is the total number of the feeders in the DN.

Low value of index $I V^{h}$ indicates a low voltage drop, meaning a higher quality voltage profile.

(5) Sum of the Squared Voltage Deviation is defined by expression:

$$
I V D^{h}=\sum_{k=1}^{N}\left(V_{r}^{h}-V_{k}^{h}\right)^{2}
$$

where $V_{k}^{h}$ is the voltage magnitude of $k$-th distribution transformer in $h$-th DN configuration.

Low values of index $I V D^{h}$ indicate a high quality voltage profile.

(6) Critical Current Reserve of the Feeders is defined by expression [39]:

$$
I J^{h}=\frac{1}{\min \left(\frac{I_{i j}^{r}-I_{i j}^{h}}{I_{i j}^{r}}\right)_{\substack{i=1, N F \\ j=1, N F S i}}}
$$

where:

$N F S i$ is the total number of the sections in $i$-th feeder;

$I_{i j}^{r}$ is the rated current of $i$-th section in $j$-th feeder;

$I_{i j}^{h}$ is the magnitude of the actual current in $i$-th section of $j$-th 
feeder in $h$-th DN configuration.

Low values of index $I J^{h}$ indicate great current reserve in the feeders, meaning higher security in the DN.

(7) Critical Current Reserve of the Supply Transformers is defined by expression [39]:

$$
I S^{h}=\frac{1}{\min \left(\frac{I_{T S i}^{r}-I_{T S i}^{h}}{I_{T S i}^{r}}\right)_{i=1, N T S}}
$$

where:

$I_{T S i}^{r}$ is the rated current in $i$-th supply transformer;

$I_{T S i}^{h}$ is the magnitude of actual current in $i$-th supply transformer in $h$-th $\mathrm{DN}$ configuration.

Low values of index $I S^{h}$ indicate great current reserve in the supply transformers, meaning higher security in the DN.

The importance of each particular index depends on the regime and the type of the DN. For example, in the normal operating condition of the distribution system, real power of the DG, power losses as well as the voltage profile have the highest priority. However, in the emergency state, the highlighted issues are the current balance of the supply transformers, current balance of the feeders, as well as, the voltage profile. Similarly, in the heavy loaded urban DN, a balance between supply transformers and a balance between feeders could be of the most importance. On the other hand, in the rural DN with long medium voltage distribution lines, serious problems could be the voltage profile in the $\mathrm{DN}$ and large voltage drop at the end customer. Using the proposed set of indices, the operation engineers have a detailed view on the overall system performances of the DN with DG.

\section{APPLICATIONS}

\section{a) Test network}

The test network used in all case studies is the IEEE 34-node test feeder [41], Fig. 2. To keep it simple, the in-line autotransformer 24.9/4.16 kV/kV from the original IEEE 34 test feeder is replaced with the line and the network is modeled with the single voltage level. Base voltage of the network is $V_{b}=24.9$ $\mathrm{kV}$, and the reference voltage is $V_{\text {ref }}=25.647 \mathrm{kV}$.

\section{b) Case Studies}

The following DMS functions in the IEEE 34 DN with DG are simulated: load estimation using fuzzy set approach [23], state estimation, single-phase power flow in the DN with balanced loads [10], three-phase power flow in the DN with unbalanced load [11], voltage regulation in the PV node by DG's reactive power control, fault analysis using hybrid compensation method [33] in 5x5 network representation, loss allocation using proportional sharing method (PS), squared demand method (SD) and direct loss coefficients (DLC) method [28]. Finally, the proposed set of system performance indices in the DN with DG is calculated.

\section{c) Results}

The Load Estimation in the IEEE $34 \mathrm{DN}$ with the DG's at nodes 23, 27 and 28 is shown on the Fig. $3 . S_{\text {ins }}$ on Fig. 3 is the rated power, and $\mathrm{P}_{\text {est }}$ and $\mathrm{Q}_{\text {est }}$ are the estimated real and the reactive load of nodes, respectively. The voltage profile obtained by State Estimation in the IEEE 34 DN with the DG's at nodes 23, 27 and 28, D-SCADA, the Remote Voltage Measurement Units (RMU-V) in the nodes 10, 17, and the Current Measurement Units (RMU-C) in the nodes 9, 25, 26, are shown on the Fig. 4. Test results indicate that state estimation improves the forecasted load data by using real-time measurements. Experience shows that power flow measurements are more effective in bad data identification than current measurements [19]. In addition, the presence of DGs in the DN improves the quality of state estimation in the DN, since the voltages in the DG's nodes are observed through the RMUs.

Fig 5. shows three-phase power flow simulation in the IEEE $34 \mathrm{DN}$ with and without DG at node $23\left(P_{g}=300 \mathrm{~kW}\right)$ and unbalanced loads. Fig. 6 shows the voltage profile in the IEEE 34 DN for the different voltage level of the DG at node 23. Fig. 7 shows the voltage regulation in the PV node 23 by reactive power control of the DG. The applied power flow method [11] is very robust. A monotonous convergence pattern has been observed for the radial power flow and for break point voltage compensation. The PV node compensation converges almost monotonically. The slight fluctuation of the maximum voltage mismatch is caused by introduction of other reactive power sources via capacitor switching, as well as by PV/PQ node conversion [11].

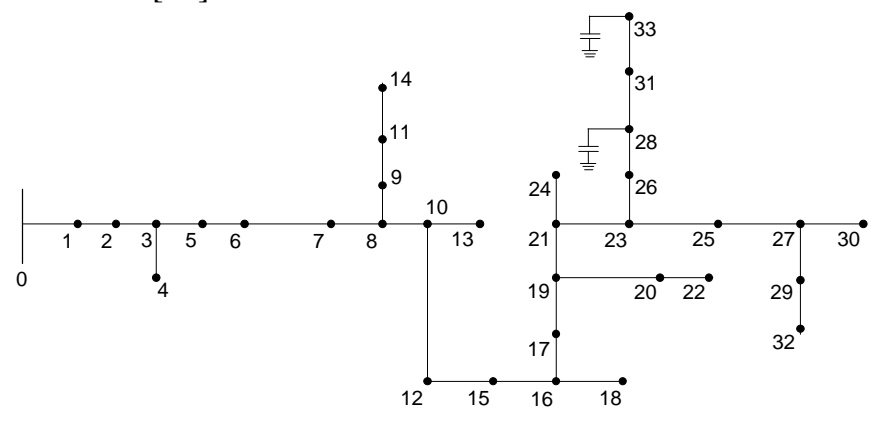

Fig. 2. IEEE 34 node test feeder.

Fig. 8 and Fig. 9 show the impact of DG in the node 23 on the short circuits in the IEEE 34 DN. Fig. 8 shows post fault-phase $a b c$, neutral wire and ground currents in the DN without DG, in case of the fault "b-c line to ground" at node 10, without DG. Fig 9 shows post-fault currents in the IEEE 34 DN with DG at node 23 in case of the same fault. Real power of the DG in fault analysis is $P_{g}=900 \mathrm{~kW}$, voltage of the DG is $V_{g}=24.5 \mathrm{kV}$, calculated reactive power of the DG, $Q_{g}=120 \mathrm{kVAr}$. The internal impedance of generator is $Z_{g e n}=(0.6+j 1.5) \Omega$, and the system equivalent impedance at the substation $\mathrm{HV} / \mathrm{MV}$ (delta/grounded wye) is $Z_{s y s}=(5+j 5) \Omega$. It can be seen that current in phase a is almost doubled in the case with DG. However, current through the neutral wire is less $50 \%$ in the case with DG.

Fig. 10 shows the Loss Allocation in the passive IEEE 34 


\section{Accepted Paper}

DN, using PS method, SD method and DLC loss allocation method. Fig. 11 shows the Loss Allocation in the IEEE 34 DN with DG at node $23\left(P_{g}=150 \mathrm{~kW}, V_{g}=24.9 \mathrm{kV}\right)$, using the same methods.

The impact of the DG connected to the node 23, (PV node, synchronous generator, $P_{g}=150 \mathrm{~kW}, V_{g}=24.9 \mathrm{kV}$, calculated reactive input power $Q_{g}=505 \mathrm{kVAr}, P_{g \max }=600 \mathrm{~kW}, Q_{g} \min =300$ $\mathrm{kVAr}, Q_{\text {gmax }}=600 \mathrm{kVAr}$ ) on the integral system performance of the IEEE 34 DN with balanced load, is shown on Table I. The DG in the considered DN, reduced the real power losses, improved the voltage profile, increased the current reserve of the feeder and supply transformer. The total feeder current in the considered DN with DG in the node 23, decreased about $60 \%$ when compared with the passive DN.

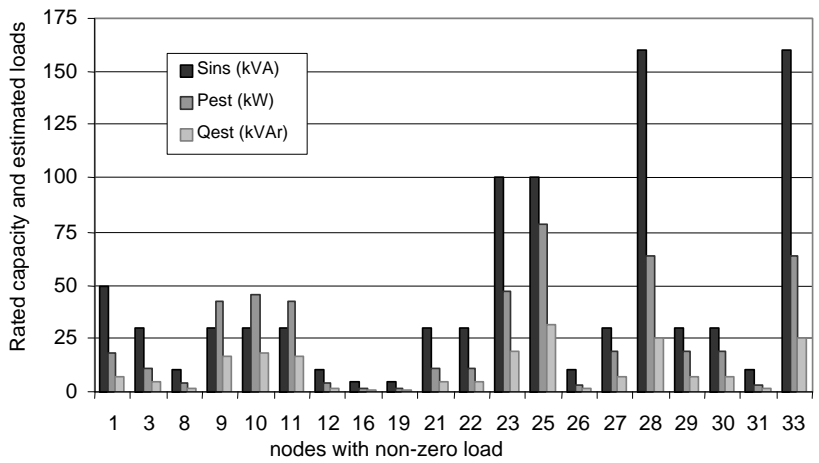

Fig. 3. Load Estimation in IEEE $34 \mathrm{DN}$ with the DGs at node 23, 27 and 28, balanced load.

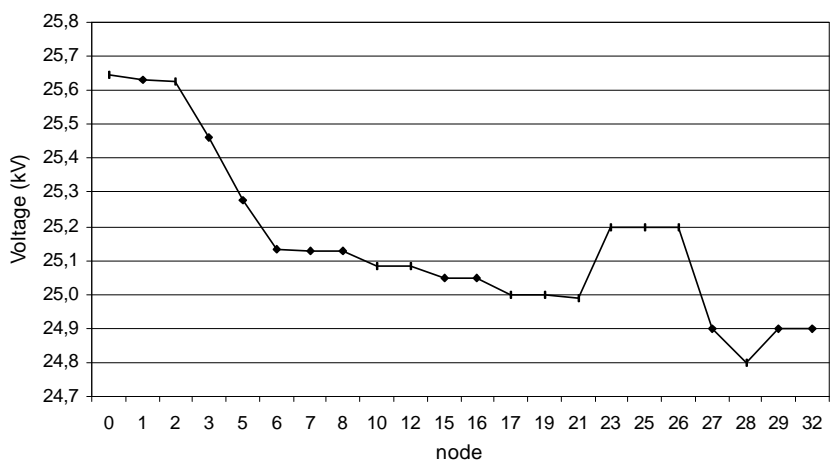

Fig. 4. State Estimation: Voltage profile in IEEE $34 \mathrm{DN}$ with the DGs at node 23,27 and 28 , balanced load.

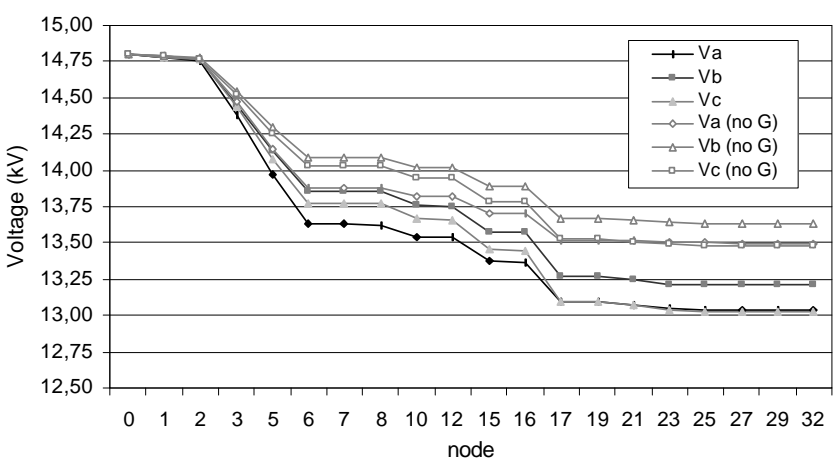

Fig. 5. Three-Phase Power flow in the IEEE $34 \mathrm{DN}$ with un-balanced load, with/without DG, $P_{g}=300 \mathrm{~kW}, Q_{g}=184 \mathrm{kVAr}, V_{g}=23.450 / \sqrt{3} \mathrm{kV}$.

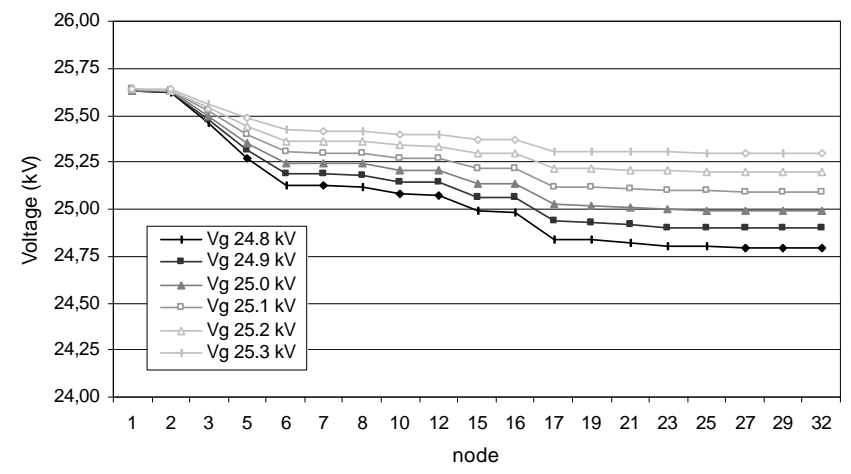

Fig. 6. Different Voltage profiles due to the voltage regulation in the PV node 23, $P_{g}=350 \mathrm{~kW}$; balanced load.

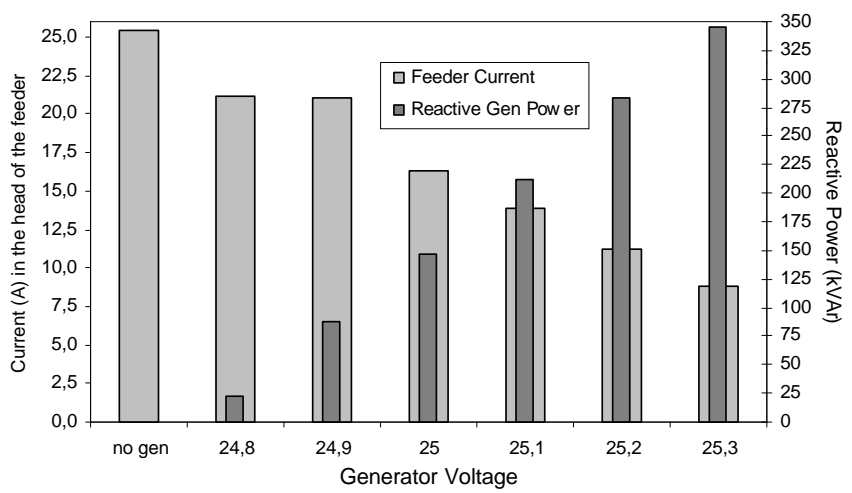

Fig. 7. Voltage regulation by Reactive Power Control in the PV node 23, $P_{g}=350 \mathrm{~kW}$, balanced load.

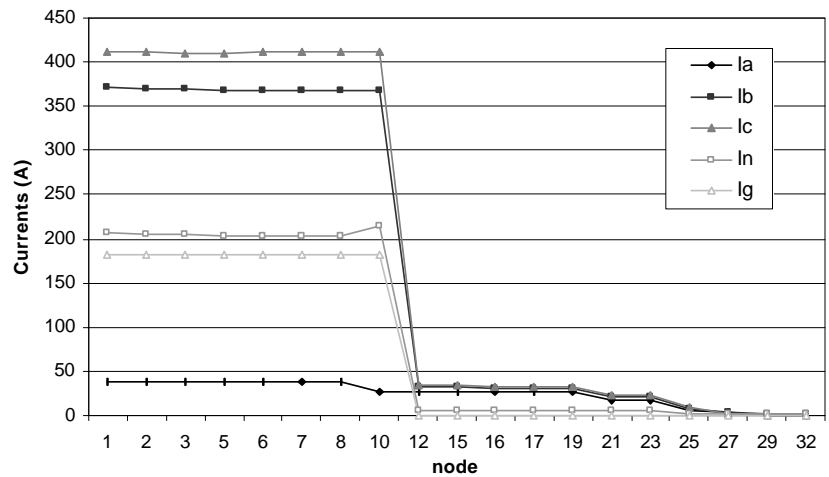

Fig. 8. Fault Analysis: Post-fault currents for the fault "double line to ground phases $\mathrm{b}$ and c" at node 10; DN with un-balanced load, with multi-grounded neutral wire, without DG.

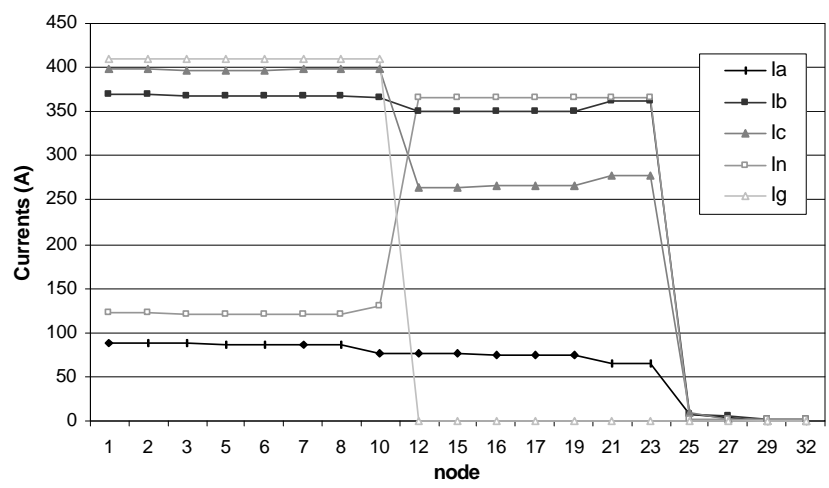

Fig. 9. Fault Analysis: Post-fault currents for fault "double line to ground phases b and c" at node 10; DN with un-balanced load, with multi-grounded neutral wire, with DG at node $23 P_{g}=900 \mathrm{~kW}$. 


\section{Accepted Paper}

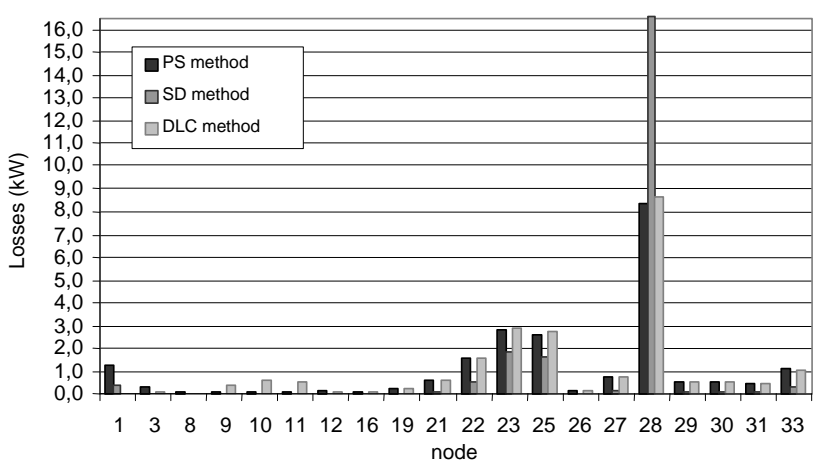

Fig. 10. Loss allocation in the IEEE $34 \mathrm{DN}$ with balanced load without DG, using PS, SD and DLC method.

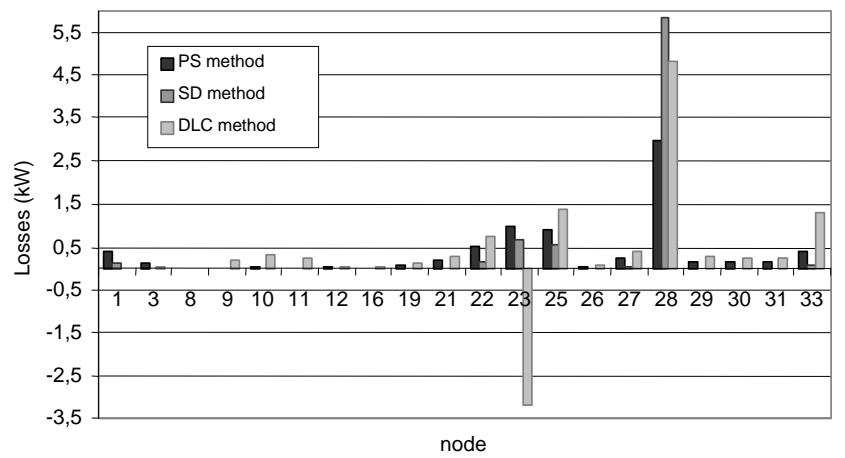

Fig. 11. Loss allocation in the IEEE $34 \mathrm{DN}$ with balanced load, with DG (PV) at node $23, P_{g}=150 \mathrm{~kW}$, using PS, SD and DLC method.

TABLE I

IMPACT OF THE DG IN THE NODE 23 ON THE SYSTEM PERFORMANCE.

\begin{tabular}{|l|c|c|}
\hline \multicolumn{1}{|c|}{ Index } & with DG & without DG \\
\hline Feeder current (A) & 9.5 & 25.4 \\
\hline Total power losses (kW) & 7.7 & 21.6 \\
\hline Total real DG power & 0.25 & 0.00 \\
\hline Total reactive DG power & 0.83 & 0.00 \\
\hline Maximum voltage drop (\%) & 3.36 & 5.37 \\
\hline Sum of the squared voltage deviation & 5.52 & 7.21 \\
\hline Current reserve of the feeder & 1.037 & 1.054 \\
\hline Current reserve of the transformer HV/MV & 1.025 & 1.034 \\
\hline
\end{tabular}

\section{CONCLUSIONS}

This paper reports some aspects of the integration of the DGs in the DMS. The following DMS functions in the DNs with DGs are considered: load (state) estimation, power flow calculation, voltage regulation, fault analysis and network reconfiguration.

The impact of the DG on the overall performances of the distribution systems in steady state, is also investigated. A set of indices for observing performances of the distribution systems with DGs based on power system analysis is proposed. The DG in the considered case studies reduced significantly the power losses, improved the voltage profile, increased the current reserve of the feeder and supply transformer HV/MV. However, observations based on experience and simulations have shown that the integration of DGs into DNs could create safety and technical problems like increasing the losses and contributing to the fault currents.

In order to observe losses in the DNs with DGs, the proportional sharing loss allocation method (PS), squared demand loss allocation method (SD) and direct loss coefficients (DLC) method are employed and the results are compared. The results of simulation show that the most reasonable loss allocation among these three methods is obtained by DLC loss allocation method. One characteristic of the DLC method is the possibility of negative loss allocations to those DGs "well" positioned in the DN. Loss allocated to the nodes in the DNs without DGs obtained by PS and DLC methods are very similar. However, in presence of DGs, neither the linear-proportional nor squared demand loss allocation gives reasonable results. This is due to the fact that power losses in the real life DNs with DGs are a non-linear function.

\section{ACKNOWLEDGMENT}

The authors would like to thank UNESP - Ilha Solteira, SP, Brazil, for the provision of facilities. R. M. Ciric is grateful to the Fundação de Amparo à Pesquisa do Estado de São Paulo (FAPESP) for its financial support to undertake this research (Project no. 00/12099-1). The authors would like to thank the ELUCID Solutions S.A., Sao Paulo, SP, Brazil, for their financial support and commitment to this project, FEPISA 0032001 .

\section{REFERENCES}

[1] N. Nichols, "The electrical considerations in cogeneration," IEEE Trans. on Indus. Appl., vol. IA-21, pp. 754-761, 1985.

[2] P. A. Nobile, "Power system studies for cogeneration: What's really needed?," IEEE Trans. on Indus. Appl., vol. IA-23, pp. 777-785, 1987.

[3] Y. Pourcin, J. Fourgous, and B. Battalia, "Technical and economic aspects of the connection of small generating plant to public MV and LV distribution networks operated by Electricite de France", in Proc. of the 7th International Conference On Electric Distribution, CIRED, Belgium 1983 , vol. a. 02.

[4] R. Dugan and D. Rizy, "Electric distribution problems associated with the interconnection of small, dispersed generation devices," IEEE Trans. on Power Apparatus and Systems, vol. PAS-103, no. 6, pp. 1121-1127, June 1984.

[5] S. K. Salman and I. M. Rida, "Investigating the impact of embedded generation on relay settings of utilities' electrical feeders," IEEE Trans. on Power Delivery, vol. 16, no. 2, pp. 246-251, Apr. 2001

[6] S. K. Salman, "Optimising system losses by effective communication between embedded generators and distribution networks," International Conference and Exhibition on Protecting Electrical Networks and Quality of Supply, London 1997.

[7] E. Lakervi and E. J. Holmes, Electricity Distribution Network Design, IEE Power Engineering Series 21, London: Peter Peregrines Ltd. On behalf of the IEE, 1995

[8] N. Jenkins, R. Allan, P. Crossley, D. Kirschen, and G. Strbac, Embedded Generation, London: IEE Power \& Energy Series 31, 2000.

[9] G. Chelli, F.Pilo, G. Carpinelli, and A. Russo, "Distributed generation setting and sizing under uncertainty," in Proc. of the IEEE Porto Power Tech Conference, Porto 2001, DRS4-376.

[10] D. Shirmohammadi, H. W. Hong, A. Semlyen, and G. X. Luo, "A compensation-based power flow method for weakly meshed distribution and transmission networks," IEEE Trans. on Power Systems, vol. 3, no. 2, pp.753-762, May 1988.

[11] C. S. Cheng and D. Shirmohammadi, "A three-phase power flow method for real-time distribution system analysis," IEEE Trans on Power Systems, vol. 10, no. 2, pp.671-769, May 1995.

[12] G. X. Luo and A. Semlyen, "Efficient load flow for large weakly meshed networks," IEEE Trans. on Power Systems, vol. 5, no. 4, pp. 1309-1316, Nov. 1990

[13] D. Rajicic, R. Ackovski, and R. Taleski, "Voltage correction power flow," IEEE Trans. on Power Delivery, vol. 9, no. 2, pp.1056-1062, Apr. 1994. 
[14] D. Rajicic and A. Dimitrovski, "A new method for handling PV nodes in backward/forward power flow for radial and weakly meshed networks," in Proc. of IEEE Porto Power Tech Conference, Porto 2001, PS03-286.

[15] A.K.Ghosh, D.L.Lubkeman, M.J.Downey, R.H.Jones, "Distribution circuit state estimation using a probabilistic approach", IEEE Trans. on Power Systems, vol. 12, pp. 45-51, Feb. 1997.

[16] M.K. Celik, W.H.Edwin Liu, "A practical distribution state estimation calculation algorithm", in Proceedings of the 1999 IEEE Power Engineering Society Winter Meeting, New York, USA.

[17] V. Miranda, J. Pereira, J.T. Saraiva, "Load allocation in DMS with a fuzzy May 2000.

IEEE Trans. on Power Systems, vol. 15, pp. 529-534,

[18] I. Roytelman, S.M.Shahidehpour, "State estimation for electric power distribution systems in quasi real-time conditions", IEEE Trans. on Power Delivery, vol. 8, pp. 2009-2015, Oct. 1993.

[19] M.E.Baran, A.W.Kelley, "A branch-current based state estimation method for distribution systems", IEEE Trans. on Power Systems, vol. 10, pp. 483-491, Feb. 1995.

[20] C.N.Liu, J.H.Teng, W.H.E. Liu, "Distribution system state estimation", IEEE Trans. on Power Systems, vol. 10, pp. 229-240, Feb. 1995.

[21] H.C. Kuo, Y.Y.Hsu, "Distribution system state estimation and service restoration using a fuzzy set approach", IEEE Trans. on Power Delivery, vol. 8, pp. 1950-1957, Oct. 1993.

[22] K.N. Miu, J. Wan, "Sensitivity-based load estimation for radial unbalanced distribution networks", in Proceedings of the 2002 IEEE Power Engineering Society Winter Meeting, New York, USA

[23] R. M. Ciric, D. S. Popovic, and A. T. Saric, "Fuzzy set theory - A solution for the problem of data uncertainty in the distribution management system," in Proc. of DistribuTECH, Madrid 1999.

[24] N. C. Scott, D. J. Atkinson, and J. Morrell, "Use of load control to regulate voltage on distribution networks with embedded generation," IEEE Trans. on Power Systems, vol. 17, no. 2, pp. 510-515, May 2002.

[25] N.D. Hatziargyriou, T.S. Karakatsanis, M. Papadopoulos, "Probabilistic load flow in distribution systems containing dispersed wind power generation", IEEE Trans. on Power Systems, vol. 8, no. 1, pp. 159-165, Feb. 1993

[26] N.D. Hatziargyriou, T.S. Karakatsanis, M. Papadopoulos, "The Effect of wind parks on the operation of voltage control devices", Proceedings of CIRED 97, IEE Conference Publication no. 438, 1997, pp. 530.1-5.30.5.

[27] A. J. Conejo, F. D. Galiana, and I. Kockar, "Z-bus loss allocation," IEEE Trans on Power Systems, vol. 16, no. 1, pp. 105-110, Feb. 2001.

[28] J. Mutale, G. Strbac, S. Curcic, and N. Jenkins, "Allocation of losses in distribution systems with embedded generation," IEE Proc.-Gener. Trans. Distrib., vol. 147, no. 1, pp. 7-14, Jan. 2000.

[29] T.H. Chen, M.S.Chen, W.J. Lee, P. Kotas, P.V. Olinda, "Distribution system short circuit analysis - a rigid approach", IEEE Trans. on Power Systems, vol. 7, no. 1, pp. 444-450, Feb. 1992.

[30] G. Gross, H.W. Hong, "A two step compensation method for solving short circuit problems", IEEE Trans. on Power Apparatus and Systems, vol. PAS-101, no. 6, pp. 1322-1331, June 1982.

[31] F. Alvarado, S. Mong, M. Enns, "A fault program with macros, monitors and direct compensation in mutual groups"”, IEEE Trans. on Power Apparatus and Systems, vol. PAS-104, no. 5, pp. 1109-1120, May 1985.

[32] V. Brandwajn, W.F. Tinney, "Generalised method of fault analysis", IEEE Trans. on Power Apparatus and Systems, vol. PAS-104, no. 6, pp. 13011306, June 1985.

[33] X. Zhang, F. Soudi, D. Shirmohammadi, and C. S. Cheng, "A distribution short circuit analysis approach using hybrid compensation method," IEEE Trans. on Power Systems, vol.10, no. 4, pp. 2053-2059, Nov. 1995.

[34] A. Merlin, H. Back, "Search for a minimal-loss operating tree configuration for un-urban power distribution system ", in Proc. of PSCC, Cambridge 1975, paper 1.2/6.

[35] Q. Zhou, D. Shirmohammadi, W.-H.Edwin Liu, "Distribution feeder reconfiguration for operation cost reduction", IEEE Trans. on Power Systems, vol. 12, no. 2, pp. 730-735, May 1997.

[36] K. Kim, Y. Ko, K.H. Hung, "Artificial neural network based feeder reconfiguration for loss reduction in distribution systems", IEEE Trans. on Power Delivery, vol. 8, pp. 1356-1366, 1993.

[37] Q. Zhou, D. Shirmohammadi, W.-H. Edwin Liu, "Distribution feeder reconfiguration for service restoration and load balancing", IEEE Trans. on Power Systems, vol. 12, no. 2, pp. 724-729, May 1997.
[38] K.N. Miu, H.-D. Chiang, B.Yan, G. Darling, "Fast service restoration for large-scale distribution systems with priority customers and constraints", IEEE Trans. on Power Systems, 0-7803-3713-1/97.

[39] D.S. Popovic, R.M. Ciric, "A multi-objective algorithm for distribution networks restoration", IEEE Trans. on Power Delivery, vol. 14, no. 3, pp. 1134-1141, July 1999.

[40] N.D.R. Sarma, S. Ghosh, K.S. Prakasa Rao, M. Srinivas, "Real time service restoration in distribution networks - A practical approach", IEEE Trans. on Power Delivery, vol. 9, no.43, pp. 2064-2070, Oct. 1994.

[41] IEEE Distribution System Analysis Subcommittee Report, "Radial distribution test feeders," in 2000 PES Summer Meeting. Available: http://ewh.ieee.org/soc/pes/dsacom/testfeeders.html

\section{BIOGRAPHIES}

Rade M. Ciric graduated from the University of Novi Sad in 1987, received his M.Sc. degree from the University of Belgrade in 1992 and gained his Ph.D. degree from University of Novi Sad, Yugoslavia, in 2000, all in electrical engineering. He has been working in Electric Power Industry of Serbia Elektrovojvodina since 1987. Since 1997 to 2001 he was an associate researcher at Group for DMS at University of Novi Sad. Since 2001 to 2002 he was a postdoctoral researcher at UNESP - Ilha Solteira, SP, Brazil.

e-mail: rciric@netscape.net

Antonio Padilha Feltrin (M'89) obtained the B.Sc. degree from EFEI, the M.Sc. and Ph.D. from UNICAMP, Brazil. He is currently an Associate Professor at UNESP - Ilha Solteira, SP, Brazil. From 1995 to 1997 he was a Visiting Faculty at ECE Department of University of Wisconsin - Madison. His main interests are in analysis and control of power systems. (UNESP - Ilha Solteira, Department of Electrical Engineering, Av. Brasil, 56 Caixa Postal 31, 15385000 Ilha Solteira, SP, Brazil).

e-mail: padilha@dee.feis.unesp.br

Iara Fernanda Ehrenberg Dossi Denis obtained the B.Sc. degree in electrical engineering from EEL LINS, Lins, SP, Brazil in 1996 and the M.Sc. from UNESP-Ilha Solteira, SP, Brazil in 2000. She is presently a Ph.D. student at UNESP-Ilha Solteira, doing research in the area of distribution systems. e-mail: iara@dee.feis.unesp.br

Luis F. Ochoa (S'01) graduated from the National Engineering University (U.N.I.) - Lima, Peru, in 2000. Presently he is a M.Sc. Student in Electrical Power Systems at the UNESP - Ilha Solteira, SP, Brazil. His main interest is distribution system analysis. e-mail: luis_ochoa@ieee.org 